\title{
Encouraging survival rates in patients with acute myocardial infarction treated with an intra-aortic balloon pump
}

\author{
S. D. A. Valk • J. M. Cheng $\cdot$ C. A. den Uil • \\ W. K. Lagrand • M. van der Ent • M. van de Sande • \\ R. T. van Domburg • M. L. Simoons
}

Published online: 18 January 2011

(C) The Author(s) 2011. This article is published with open access at Springerlink.com

\begin{abstract}
Objective To evaluate a 30-day and long-term outcome of patients with acute myocardial infarction (AMI) treated with intra-aortic balloon pump (IABP) counterpulsation and to identify predictors of a 30-day and long-term all-cause mortality.

Methods Retrospective cohort study of 437 consecutive AMI patients treated with IABP between January 1990 and June 2004. A Cox proportional hazards model was used to identify predictors of a 30-day and long-term all-cause mortality.

Results Mean age of the study population was $61 \pm 11$ years, $80 \%$ of the patients were male, and $68 \%$ had cardiogenic shock. Survival until IABP removal after successful haemodynamic stabilisation was $78 \%(n=341)$. Cumulative 30 -day survival was $68 \%$. Median follow-up was 2.9 years (range, 6 months to 15 years). In patients who survived until IABP removal, cumulative 1-, 5-, and 10-year survival was $75 \%, 61 \%$, and $39 \%$, respectively. Independent
\end{abstract}

S. D. A. Valk $(\varangle) \cdot$ J. M. Cheng $\cdot$ C. A. den Uil

M. van de Sande $\cdot$ R. T. van Domburg $\cdot$ M. L. Simoons

Department of Cardiology, Thorax Center, Erasmus MC,

Room Ba 577,'s Gravendijkwal 230,

3015 CE Rotterdam, the Netherlands

e-mail: s.valk@erasmusmc.nl

W. K. Lagrand

Department of Intensive Care Medicine,

Academic Medical Center,

Amsterdam, the Netherlands

M. van der Ent

Department of Cardiology, Maasstad Hospital,

location Zuider,

Rotterdam, the Netherlands predictors of higher long-term mortality were prior cerebrovascular accident (hazard ratio (HR), 1.8; 95\% confidence interval (CI), 1.0-3.4), need for antiarrhythmic drugs (HR, 2.3; 95\% CI, 1.5-3.3), and need for renal replacement therapy (HR, 2.3; 95\% CI, 1.2-4.3). Independent predictors of lower long-term mortality were primary percutaneous coronary intervention (PCI; HR, 0.6; 95\% CI, 0.4-1.0), failed thrombolysis with rescue PCI (HR, $0.5 ; 95 \% \mathrm{CI}, 0.3-0.9)$, and coronary artery bypass grafting (HR, $0.3 ; 95 \% \mathrm{CI}, 0.1-0.5$ ). Conclusions Despite high in-hospital mortality in patients with AMI treated with IABP, a favourable number of patients survived in the long-term. These results underscore the value of aggressive haemodynamic support of patients throughout the acute phase of AMI.

Keywords Acute myocardial infarction · Intra-aortic balloon pump · Outcome · Predictors · Survival

\section{Introduction}

The intra-aortic balloon pump (IABP) was introduced by Kantrowitz et al. in 1968 as a means of circulatory support in haemodynamically unstable patients in cardiogenic shock following acute myocardial infarction (AMI) [1]. In the years thereafter, indications for its use have expanded. Today, it is used mainly as a mechanical support device in addition to pharmacological treatment in patients with low cardiac output or sustained myocardial ischaemia. In patients with AMI, IABP reduces afterload, which leads to a more effective and easier emptying of the left ventricle which will increase cardiac output. It may also reduce myocardial ischaemia by augmenting coronary perfusion $[2,3]$. 
The IABP may improve cardiac performance and haemodynamic parameters while the ischaemic myocardium recovers. IABP also decreases the incidence of recurrent ischaemia and infarct-related artery re-occlusion after reperfusion therapy, improves survival when used in conjunction with thrombolytic therapy compared with thrombolytic therapy alone, and enhances rescue percutaneous coronary intervention (PCI) for failed thrombolysis. Other indications for IABP use are mechanical complications of AMI, refractory ventricular arrhythmias, support during high-risk PCI and preoperative support for high-risk cardiac surgery [4-8].

Despite increasing experience, more frequent utilisation and broadening indications for IABP use, little is known about the long-term outcome after IABP treatment of AMI. This study was conducted to investigate the in-hospital and long-term outcome of patients with AMI treated with IABP, and to identify predictors of in-hospital and long-term survival.

\section{Methods}

\section{Patient Selection}

We conducted a single-centre retrospective follow-up study. All 437 consecutive patients admitted with AMI and treated with IABP between January 1990 and June 2004 were included. Data were acquired from patient records and local databases. Indications for IABP use were AMI with cardiogenic shock, haemodynamic support during PCI, refractory or post-myocardial infarction angina, valvular dysfunction, mechanical complication, or refractory ventricular arrhythmia after AMI.

\section{Balloon Pump}

From 1990 to 1995, Datascope 9.5 and 10.5 French catheters were used. Between 1995 and 2000, 9-French Arrow catheters were used. From 2000 until the end of 2004, 8-French Arrow catheters were used.

\section{Study Definitions}

Cardiogenic shock was defined as systolic blood pressure $\leq 90 \mathrm{mmHg}$ due to impaired cardiac function diagnosed by echocardiography and associated with clinical signs of decreased cardiac output not responsive to optimalisation of filling pressures. Relevant complications were limb ischaemia requiring IABP removal, bleeding, embolic and thrombotic events, need for vascular surgery, and infection. Limb ischaemia was defined as diminished or absent peripheral pulsations. Bleeding complications were classified as major and minor. Major bleeding was defined as bleeding requiring red cell transfusion, minor bleeding as any access site bleeding. IABP-related infection was defined as fever with an increase in white blood cell count, C-reactive protein $(>5 \mathrm{mg} / \mathrm{l})$, and signs of local infection. Blood and catheter tip cultures to confirm the diagnosis of IABP-related infection were not available. Left ventricular systolic function (LVF) was estimated qualitatively by echocardiography. LVF was classified as normal, moderate, impaired, or severely depressed.

Follow-up

Follow-up for vital status was obtained by contacting the civil registry and was complete in $99.5 \%$ at the reference date of December 2004. For two patients who moved abroad, the latest available information was used. Minimal follow-up duration was 6 months.

\section{Statistical Analysis}

Discrete variables were compared with the $\chi^{2}$ or Fisher's exact test when appropriate and are presented as percentages. Continuous variables were compared with the Student's $t$ test and are presented as mean \pm standard deviation. Survival data were analysed using the KaplanMeier method. Survival curves were compared with the log-rank test. Univariate and multivariate Cox proportional hazard regression analyses were performed to delineate predictors of in-hospital and long-term survival. Preselected variables were age, gender, blood pressure and heart rate, diabetes, hypertension, smoking, hypercholesterolaemia, positive family history, peripheral vascular disease, prior cerebrovascular accident (CVA), AMI, PCI, coronary artery bypass grafting (CABG), infarct location, extent of vessel disease, LVF, treatment during IABP use, cardiopulmonary resuscitation (CPR), and IABP running time.

\section{Results}

\section{Baseline Characteristics}

The baseline characteristics of the study population are presented in Table 1. The mean age of the population was $61 \pm 11$ years. Eighty per cent of the patients were male. The median follow-up was 2.9 years (range, 6 months to 15 years). Indications for IABP use were cardiogenic shock $(68 \%)$, haemodynamic support during PCI $(6 \%)$, high-risk $\mathrm{CABG}(17 \%)$, refractory or post-myocardial infarction angina (9\%), valvular dysfunction or mechanical 
Table 1 Baseline and clinical characteristics of patients with AMI treated with IABP

\begin{tabular}{|c|c|}
\hline & Total $(n=437)$ \\
\hline Age (years) & $61 \pm 11$ \\
\hline Male gender $(\%)$ & 80 \\
\hline \multicolumn{2}{|l|}{ Risk factors $(\%)$} \\
\hline Diabetes & 20 \\
\hline Hypertension & 36 \\
\hline Smoking & 51 \\
\hline Hypercholesterolaemia & 30 \\
\hline Peripheral vascular disease & 10 \\
\hline \multicolumn{2}{|l|}{ History $(\%)$} \\
\hline CVA/TIA & 8 \\
\hline AMI & 50 \\
\hline CABG & 10 \\
\hline PCI & 11 \\
\hline Systolic blood pressure (mmHg) & $108 \pm 28$ \\
\hline Diastolic blood pressure $(\mathrm{mmHg})$ & $65 \pm 17$ \\
\hline Heart rate (bpm) & $94 \pm 25$ \\
\hline \multicolumn{2}{|l|}{ Left ventricular function $(\%)$} \\
\hline Normal/moderate & 19 \\
\hline Impaired & 24 \\
\hline Severely depressed & 25 \\
\hline Unknown & 32 \\
\hline Three vessel/left main stem coronary disease (\%) & 44 \\
\hline Cardiogenic shock (\%) & 68 \\
\hline \multicolumn{2}{|l|}{ Infarct location $(\%)$} \\
\hline Antero-septal wall & 64 \\
\hline Infero-posterior wall & 36 \\
\hline Reperfusion therapy (\%) & 84 \\
\hline Primary PCI & 40 \\
\hline Thrombolysis & 25 \\
\hline Rescue PCI & 21 \\
\hline CABG & 25 \\
\hline No reperfusion therapy & 16 \\
\hline \multicolumn{2}{|l|}{ Treatment during ICCU stay $(\%)$} \\
\hline Inotropic agents & 72 \\
\hline Cardiopulmonary resuscitation & 25 \\
\hline Mechanical ventilation & 54 \\
\hline Antiarrhythmic drugs & 43 \\
\hline Renal replacement therapy & 4 \\
\hline \multicolumn{2}{|l|}{ IABP running time $(\%)$} \\
\hline 1 day & 31 \\
\hline 2 to 5 days & 51 \\
\hline$\geq 6$ days & 18 \\
\hline
\end{tabular}

Data are presented as mean $\pm \mathrm{SD}$, or as a percentage

$A M I$ acute myocardial infarction, $I A B P$ intra-aortic balloon pump, $S D$ standard deviation, CVA cerebrovascular accident, TIA transient ischaemic attack, $C A B G$ coronary artery bypass grafting, $P C I$ percutaneous coronary intervention, $\mathrm{mmHg}$ millimetres of mercury, bpm beats per minute, ICCU intensive cardiac care unit complications $(8 \%)$, or refractory ventricular arrhythmias $(1 \%)$. In some patients there was more than one indication for IABP support. Reperfusion therapy was performed in $84 \%$. Forty per cent of the patients were treated with primary PCI, 25\% with thrombolysis, $21 \%$ had a rescue PCI and $25 \%$ were treated with emergency CABG.

\section{Predictors of Successful IABP Weaning}

Baseline characteristics of patients who survived until IABP removal $(78 \%, n=341)$ are presented in Table 2 . IABP running time in this group was 1 day in $23 \%$, $2-5$ days in $57 \%$, and $\geq 6$ or more days in $20 \%$ of these patients. Patients with IABP running time $\geq 6$ days had a significantly lower systolic blood pressure and were more often in cardiogenic shock. Prior AMI, prior CABG, diminished LVF, administration of inotropic or antiarrhythmic drugs (AAD) and need for resuscitation were also significantly more frequent in this subgroup as compared with an IABP running time of $2-5$ days. They were also less frequently treated with primary PCI.

\section{Thirty-Day and Long-term Outcome}

Cumulative survival was $58 \%, 47 \%$, and $30 \%$ at 1,5 , and 10 years follow-up, respectively. In the patient group who survived until IABP removal, cumulative survival was $75 \%, 61 \%$, and $39 \%$ at 1,5 , and 10 years follow-up, respectively. Patients with IABP running time of $\geq 6$ days had a significantly higher long-term mortality compared with patients with an IABP running time of 2-5 days $(p<0.05)$ (Fig. 1).

Adjusted predictors of 30-day mortality are presented in Table 3. Age (hazard ratio (HR) 1.03; 95\% CI, 1.0-1.06), cardiogenic shock (HR, 2.7; 95\% CI, 1.2-6.0), the need for inotropic agents (HR, 7.5; 95\% CI, 2.8-19.6) and CPR (HR, 2.3; 95\% CI, 1.2-4.2) were independently associated with lower 30-day survival. Independent predictors of higher 30-day survival were treatment with primary PCI (HR, 0.2; 95\% CI, 0.1-0.5), thrombolysis (HR, 0.1; 95\% CI, 0.0-0.8), rescue PCI (HR, 0.3; 95\% CI, 0.1-0.6), and CABG (HR, 0.1; 95\% CI, 0.0-0.3).

Adjusted predictors of long-term mortality in patients who survived until IABP removal are presented in Table 3. Prior CVA or transient ischaemic attack (TIA; HR, 1.8; 95\% CI, 1.0-3.4), need for AAD (HR, 2.3; 95\% CI, 1.53.3 ), and renal replacement therapy (HR, 2.3; 95\% CI, 1.2 4.3) were independently associated with lower long-term survival. Independent predictors of higher long-term survival were primary PCI (HR, 0.6; 95\% CI, 0.4-1.0), rescue PCI (HR, 0.5; 95\% CI, 0.3-0.9), and CABG (HR, 0.3; 95\% CI, 0.1-0.5). 
Table 2 Baseline and clinical characteristics of patients with AMI who survived until IABP removal, stratified by IABP running time

\begin{tabular}{|c|c|c|c|c|c|}
\hline & Total $(n=341)$ & 1 day $(n=77)$ & $2-5$ days $(n=195)$ & $\geq 6$ days $(n=69)$ & $p$ value \\
\hline Age (years) & $61 \pm 11$ & $63 \pm 11$ & $60 \pm 11$ & $60 \pm 11$ & 0.1 \\
\hline Male gender $(\%)$ & 80 & 79 & 78 & 84 & 0.5 \\
\hline \multicolumn{6}{|l|}{ Risk factors $(\%)$} \\
\hline Diabetes & 21 & 20 & 22 & 17 & 0.7 \\
\hline Hypertension & 37 & 46 & 38 & 26 & 0.1 \\
\hline Smoking & 51 & 46 & 50 & 60 & 0.3 \\
\hline Hypercholesterolaemia & 32 & 36 & 31 & 29 & 0.6 \\
\hline Peripheral vascular disease & 10 & 15 & 9 & 7 & 0.2 \\
\hline \multicolumn{6}{|l|}{ History (\%) } \\
\hline CVA/TIA & 8 & 8 & 9 & 7 & 0.9 \\
\hline AMI & 50 & 60 & 44 & 57 & $<0.05$ \\
\hline CABG & 10 & 14 & 6 & 16 & $<0.05$ \\
\hline PCI & 13 & 18 & 12 & 9 & 0.2 \\
\hline Systolic blood pressure $(\mathrm{mmHg})$ & $110 \pm 28$ & $119 \pm 25$ & $110 \pm 30$ & $103 \pm 26$ & $<0.01$ \\
\hline Diastolic blood pressure $(\mathrm{mmHg})$ & $67 \pm 17$ & $71 \pm 16$ & $66 \pm 17$ & $63 \pm 16$ & $<0.05$ \\
\hline Heart rate (bpm) & $92 \pm 25$ & $87 \pm 25$ & $91 \pm 26$ & $97 \pm 22$ & 0.1 \\
\hline Left ventricular function (\%) & & & & & $<0.001$ \\
\hline Normal/moderate & 22 & 29 & 21 & 17 & \\
\hline Impaired & 28 & 23 & 30 & 29 & \\
\hline Severely depressed & 24 & 9 & 25 & 39 & \\
\hline Unknown & 26 & 39 & 24 & 15 & \\
\hline Three vessel/left main stem coronary disease $(\%)$ & 43 & 45 & 42 & 46 & 0.4 \\
\hline Cardiogenic shock $(\%)$ & 61 & 48 & 63 & 71 & $<0.05$ \\
\hline Infarct location $(\%)$ & & & & & 0.4 \\
\hline Antero-septal wall & 63 & 60 & 66 & 54 & \\
\hline Infero-posterior wall & 37 & 40 & 34 & 46 & \\
\hline \multicolumn{6}{|l|}{ Reperfusion therapy (\%) } \\
\hline Primary PCI & 41 & 51 & 43 & 25 & $<0.01$ \\
\hline Thrombolysis & 26 & 19 & 26 & 34 & 0.1 \\
\hline Rescue PCI & 21 & 13 & 21 & 30 & 0.1 \\
\hline CABG & 30 & 35 & 28 & 31 & 0.5 \\
\hline No reperfusion therapy & 11 & 5 & 9 & 22 & $<0.01$ \\
\hline \multicolumn{6}{|l|}{ Treatment during ICCU stay (\%) } \\
\hline Inotropic agents & 68 & 43 & 72 & 86 & $<0.001$ \\
\hline Cardiopulmonary resuscitation & 19 & 13 & 17 & 30 & $<0.05$ \\
\hline Mechanical ventilation & 50 & 46 & 52 & 52 & 0.6 \\
\hline Antiarrhythmic drugs & 45 & 26 & 44 & 70 & $<0.001$ \\
\hline Renal replacement therapy & 4 & 0 & 5 & 7 & 0.1 \\
\hline
\end{tabular}

Data are presented as mean $\pm \mathrm{SD}$, or as a percentage

$A M I$ acute myocardial infarction, $I A B P$ intra-aortic balloon pump, $S D$ standard deviation, $C V A$ cerebrovascular accident, TIA transient ischaemic attack, $C A B G$ coronary artery bypass grafting, $P C I$ percutaneous coronary intervention, $\mathrm{mmHg}$ millimetres of mercury, $\mathrm{bpm}$ beats per minute, $I C C U$ intensive cardiac care unit

\section{IABP Use Over the Years}

Between 1990 and 1994 (period I) 116 patients were treated with IABP: from 1995 to 1999 (period II) 141 patients and between 2000 and 2004 (period III) 180 patients. Mean age was $62 \pm 9,59 \pm 12,63 \pm 11$ years in period I, II and III respectively $(p<0.05)$. No difference in the number of patients in cardiogenic shock was observed. The use of primary PCI increased from $20 \%$ in period I to $58 \%$ in period III $(p<0.001)$. The use of thrombolytic therapy $(p<0.01)$ and emergency CABG $(p<0.01)$ decreased. The utilisation of reperfusion therapy increased over time 


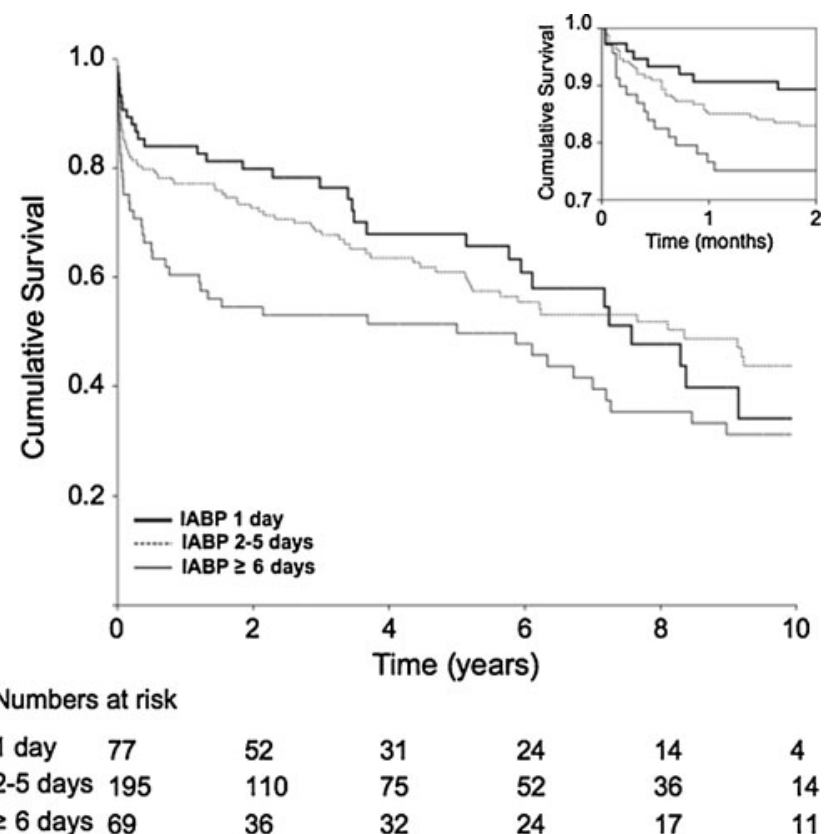

Fig. 1 Long-term survival according to IABP running time

$(p<0.01)$. Mean IABP running time decreased from three to two days between period I and III. The complication rate decreased from $28 \%$ to $9 \%(p<0.001)$ Thirty-day mortality decreased from $41 \%$ to $26 \%(p<0.05)$.

\section{IABP-Related Complications}

Complications were observed in 88 patients $(20 \%)$. The most frequently observed complications were infection
( $n=34 ; 8 \%)$, bleeding $(n=23 ; 5 \%)$, and limb ischaemia $(n=21 ; 5 \%)$. Of all bleeds, five patients had major bleeding. Limb ischaemia was transient in the majority of the cases $(n=17,81 \%)$, with either spontaneous recovery, or after IABP removal. Vascular surgery was needed in four patients $(19 \%)$.

\section{Discussion}

The main finding of this study is that the use of the IABP in patients admitted with AMI is associated with an excellent prognosis in hospital survivors. Almost half of these patients are alive after 10-year follow-up. In-hospital mortality declined over the years and was lower in patients in whom IABP support was required for a relatively short period (5 days or less).

In this study in-hospital survival was $68 \%$. Other studies have reported survival rates ranging from $71 \%$ to $79 \%$. This observation, however, must be seen in perspective to the percentage of patients in cardiogenic shock in our population (68\% compared with $19-27 \%$ in other studies) [9-12]. Mortality rates for AMI and cardiogenic shock are as high as $60 \%$ [13]. The relatively high survival rate despite a high percentage of cardiogenic shock may be due to the higher use of reperfusion therapy (84\%) in our study compared with other studies [7]. The incidence of cardiogenic shock has only slightly declined over the years but in-hospital survival increased due to increased use of reperfusion therapy [14-16]. A recent report by our group on a subgroup of patients from this present study also underlines
Table 3 Multivariate regression analysis

Only statistically significant predictors are described

$I A B P$ intra-aortic balloon pump, $A M I$ acute myocardial infarction, $H R$ hazard ratio, $C I$ confidence interval, $C A B G$ coronary artery bypass grafting, $P C I$ percutaneous coronary intervention, $C V A$

cerebrovascular accident, TIA transient ischaemic attack

\begin{tabular}{lcc}
\hline & HR & $95 \%$ CI \\
\hline Predictors of 30-day mortality in patients with AMI treated with IABP & \\
Age & 1.03 & $1.0-1.06$ \\
Cardiogenic shock & 2.7 & $1.2-6.0$ \\
Reperfusion therapy & & \\
Primary PCI & 0.2 & $0.1-0.5$ \\
Thrombolysis & 0.1 & $0.0-0.8$ \\
Rescue PCI & 0.3 & $0.1-0.6$ \\
CABG & 0.1 & $0.0-0.3$ \\
Inotropic agents & 7.5 & $2.8-19.6$ \\
Resuscitation & 2.3 & $1.2-4.2$ \\
Predictors of long-term mortality in patients with AMI who survived until IABP removal \\
CVA/TIA & 1.8 & $1.0-3.4$ \\
Reperfusion therapy & & \\
Primary PCI & 0.6 & $0.4-1.0$ \\
Rescue PCI & 0.5 & $0.3-0.9$ \\
CABG & 0.3 & $0.1-0.5$ \\
Antiarrhythmic drugs & 2.3 & $1.5-3.3$ \\
Renal replacement therapy & 2.3 & $1.2-4.3$ \\
\hline
\end{tabular}


the usefulness of IABP support in conjunction with reperfusion therapy leading to encouraging 30-day and long-term survival rates in patients with AMI complicated by cardiogenic shock [17].

Predictors of lower in-hospital survival were advanced age, diminished LVF, longer IABP running time, the need for inotropic support and resuscitation. CABG or PCI were associated with higher in-hospital survival. This is in line with the findings of Stone et al., who also found that increased age and cardiogenic shock were associated with worse in-hospital survival and that coronary revascularisation was a strong independent predictor of in-hospital survival [9].

To our knowledge, this is the first study reporting up to 15 years of follow-up of patients admitted with AMI and treated with IABP. Our results show that although initial inhospital mortality is relatively high, when discharged from the hospital alive, long-term survival was better than expected. Almost $50 \%$ of these patients are still alive after 10 years follow-up. As a large proportion of our population was in cardiogenic shock at presentation, survival is certainly better than expected.

Predictors of long-term mortality were previous CVA/ TIA, the need for AAD and renal replacement therapy. These probably represent patients in a worse clinical condition requiring additional supportive therapy. However, PCI or CABG were associated with sustained long-term survival benefit in a study by Van Domburg et al. [18]. This shows that the beneficial effect of reperfusion therapy extends beyond the acute moment [14].

Despite older age, a decline in in-hospital mortality was observed over the years which seems to be related to expanding treatment options and the increasing use of reperfusion therapy. In the latest inclusion period almost $60 \%$ underwent primary PCI. This increase in primary PCI is reflected in the decrease in emergency CABG. Nowadays even more patients admitted with AMI undergo primary PCI.

In-hospital mortality was highest on the first day after IABP insertion. This group mainly consisted of patients who could not be stabilised. Early IABP removal was possible in patients who had the IABP inserted during PCI for transient hypotension or because of a large myocardial area at risk. From days 2 to 5 in-hospital mortality was relatively low. This group represented patients who could be stabilised. IABP running time of $\geq 6$ days was associated with increased in-hospital mortality. These patients survive the first days after admission but either remain unstable or develop complications eventually leading to death.

The most frequent complications were limb ischaemia, bleeding from the IABP entry site and infection. Previously reported complication rates range from $7 \%$ to $47 \%$ [19-23]. The Benchmark registry reported a complication rate of $8.1 \%$ which is lower than observed in this study. Our complication rate may be higher due to our study definitions. Ischaemia was present when patient records mentioned diminished or absent pulsations. Detection of diminished pulsations may be subjective and may potentially lead to a higher ischaemia percentage. Infection was more prevalent $(8 \%)$ than in the Benchmark registry. This may also be caused by our less strict definition of IABPrelated infection as no definite tip or blood cultures were available to confirm the diagnosis. However, a study by Cristal et al. reported true bacteraemia and sepsis in IABP patients in $15 \%$ and $12 \%$, respectively, mainly during the first $48 \mathrm{~h}$ after insertion [24]. As shown in previous studies, complication rate decreased with the introduction of smaller French size catheters $[22,25,26]$.

\section{Limitations}

Since Erasmus MC is a tertiary referral centre, selection bias may influence our results. However, this probably leads to an underestimation of the effect as our study population consists of high-risk patients. Due to incomplete documentation of several clinical variables, information bias cannot be excluded.

\section{Conclusions}

This is, to our knowledge, the first study reporting on 15 years of follow-up in patients with AMI treated with IABP. Almost half of the in-hospital survivors are still alive after 10 years of follow-up, which is better than expected. Furthermore, in-hospital mortality was related to IABP running time, with the highest mortality during the first day (patients in severe cardiogenic shock who could not be stabilised), a decrease in mortality from days 2 to 5 and from day 6 on again a higher mortality (patients with severe impairment who did not recover). Finally, a trend towards lower in-hospital mortality was observed over the years. So, despite older age and a trend towards more cardiogenic shock, survival is quite good, and aggressive haemodynamic support is useful even up to 5 days after IABP insertion.

Open Access This article is distributed under the terms of the Creative Commons Attribution Noncommercial License which permits any noncommercial use, distribution, and reproduction in any medium, provided the original author(s) and source are credited.

\section{References}

1. Kantrowitz A, Tjonneland S, Freed PS, et al. Initial clinical experience with intra-aortic balloon pumping in cardiogenic shock. JAMA. 1968;203:135-40. 
2. Santa-Cruz RA, Cohen MG, Ohman ME. Aortic Counterpulsation: a review of the hemodynamic effects and indications for use. Catheter Cardiovasc Interv. 2006;67:68-77.

3. Kern MJ, Aguirre F, Bach R, et al. Augmentation of coronary blood flow by intra-aortic balloon pumping in patients after coronary angioplasty. Circulation. 1993;87:500-11.

4. Ohman EM, Califf RM, George BS, et al. The use of intra aortic balloon pumping as an adjunct to reperfusion therapy in acute myocardial infarction. The Thrombolysis and Angioplasty in Myocardial Infarction (TAMI) Study Group. Am Heart J. 1991;121 (3 Pt 1):895-901.

5. Ishihara M, Sato H, Tateishi $\mathrm{H}$, et al. Intra-aortic balloon pumping as the post angioplasty strategy in acute myocardial infarction. Am Heart J. 1991;122(2):385-9.

6. Sanborn TA, Sleeper LA, Bates ER, et al. Impact of thrombolytic, intra- aortic balloon pump counterpulsation, and their combination in cardiogenic shock complicating acute myocardial infarction: a report from the SHOCK Trial Registry. Should we emergently revascularize Occluded Coronaries for cardiogenic shocK? J Am Coll Cardiol. 2000;36(3 Suppl A):1123-9.

7. Barron HV, Every NR, Parsons LS, et al. The use of intra-aortic balloon counterpulsation in patients with cardiogenic shock complicating acute myocardial infarction: data from the National Registry of Myocardial Infarction 2. Am Heart J. 2001;141 (6):933-9.

8. Ishihara $\mathrm{M}$, Sato $\mathrm{H}$, Tateishi $\mathrm{H}$, et al. Intra-aortic balloon pumping as adjunctive therapy to rescue coronary angioplasty after failed thrombolytic in anterior wall acute myocardial infarction. Am J Cardiol. 1995;76(1):73-5.

9. Stone GW, Ohman EM, Miller MF, et al. Contemporary utilization and outcomes of intra-aortic balloon counter pulsation in acute myocardial infarction: the benchmark registry. J Am Coll Cardiol. 2003;41(11):1940-5.

10. Cohen M, Urban P, Christenson JT, et al. Intra-aortic balloon counterpulsation in US and non-US centres: results of the Benchmark Registry. Eur Heart J. 2003;24(19):1763-70.

11. Ferguson 3rd JJ, Cohen M, Freedman RJ, et al. The current practice of intra-aortic balloon counterpulsation: results from the Benchmark Registry. J Am Coll Cardiol. 2001;38(5):145662.

12. Goldberg RJ, Gore JM, Alpert JS, et al. Cardiogenic shock after acute myocardial infarction. Incidence and mortality from a community-wide perspective, 1975 to 1988. N Engl J Med. 1991;325(16):1117-22.

13. Hochman JS, Buller CE, Sleeper LA, et al. Cardiogenic shock complicating acute myocardial infarction- etiologies, management and outcome: a report from the SHOCK Trial Registry. Should we emergently revascularize Occluded Coronaries for cardiogenic shock? J Am Coll Cardiol. 2000;36(3 suppl A):1063-70.

14. Hochman JS, Sleeper LA, White HD, et al. One-year survival following early revascularization for cardiogenic shock. JAMA. 2001;285(2):190-2.

15. Goldberg RJ, Samad NA, Yarzebski J, et al. Temporal trends in cardiogenic shock complicating acute myocardial infarction. N Engl J Med. 1999;340(15):1162-8.

16. Goldberg RJ, Gore JM, Thompson CA, et al. Recent magnitude of and temporal trends (1994-1997) in the incidence and hospital death rates of cardiogenic shock complicating acute myocardial infarction: the second national registry of myocardial infarction. Am Heart J. 2001;141(1):65-72.

17. Cheng JM, Valk SDA, den Uil CA, et al. Usefulness of intra-aortic balloon pump counterpulsation in patients with cardiogenic shock from acute myocardial infarction. Am J Cardiol. 2009;104:327-32.

18. Van Domburg RT, Sonnenschein K, Nieuwlaat R, et al. Sustained benefit 20 years after reperfusion therapy in acute myocardial infarction. J Am Coll Cardiol. 2005;46(1):15-20.

19. Alcan KE, Stretzer SH, Wallsh E, et al. Comparison of wireguided percutaneous insertion and conventional surgical insertion of intra-aortic balloon pumps in 151 patients. Am J Med. 1983;75 (1):24-8.

20. Sanfelippo PM, Baker NH, Ewy G, et al. Experience with intraaortic balloon counter pulsation. Ann Thorac Surg. 1986;41 (1):36-41.

21. Collier PE, Liebler GA, Park SB, et al. Is percutaneous insertion of intra-aortic balloon through the femoral artery the safest technique? J Vasc Surg. 1986;3(4):629-34.

22. Scholz KH, Ragab S, von zur Muhlen F, et al. Complications of intra-aortic balloon counterpulsation. The role of catheter size and duration of support in a multivariate analysis of risk. Eur Heart J. 1998;19(3):458-65.

23. Arafa OE, Pedersen TH, Svennevig JL, et al. Vascular complications of the intra-aortic balloon pump in patients undergoing open heart operations: 15-year experience. Ann Thorac Surg. 1999;67 (3):645-51.

24. Crystal E, Borer A, Gilad J, et al. Incidence and clinical significance of bacteraemia and sepsis among cardiac patients treated with intra-aortic balloon counterpulsation pump. Am J Cardiol. 2000;86(11):1281-4.

25. Azeem T, Stephens-Lloyd A, Spyt T, et al. Intra-aortic balloon counterpulation: variations in use and complications. Int J Cardiol. 2004;94(2-3):255-9.

26. Eltchaninoff H, Dimas AP, Whitlow PL. Complications associated with percutaneous placement and use of intraaortic balloon counterpulsation. Am J Cardiol. 1993;71(4):328-32. 